\title{
Life Cycle Cost management of blower station construction for wastewater utility
}

\author{
Victor Bazhenov ${ }^{1, *}$ and Andrei Ustiuzhanin ${ }^{1,2}$ \\ ${ }^{1}$ Closed Joint Stock Company "Water and Waste Water" 1, Polkovaya street, Moscow, 127018, \\ Russia \\ ${ }^{2}$ Moscow State University of Civil Engineering (National Research University), 26, Yaroslavskoe \\ shosse, Moscow, 129337, Russia
}

\begin{abstract}
Management and Economics in construction is submitted by this article as a settlement tool for construction justification of blower stations. These buildings with powerful units are under financial provision of communal wastewater utilities. Economic management implemented by usage of LCC analyses, which supposed to support decision making process. LCC analyses refer to its application with and without consideration of discount rates (DR, DR-out, DR-with). Also investigated variants of blower types: multistage without control (v1), multistage with VFD control (v2), single stage dual vane control (v3). The result of LCC analysis (DR-out) shows, that last variant 3 is most cost-effective for investments with economy of: $26,9 \%$ to (v1) and $21,7 \%$ to (v2) under the identical duty conditions. Consideration of discount rates (DR-with) resulted the same as: $21,5 \%$ to (v1) and $19,7 \%$ to (v2). The power consumption plays a significant role in LCC estimation. The result of LCC analysis (DR-out) shows the proportion "energy/LCC": 94,9\% (v1); 87,1\% (v2); $84,5 \%$ (v3). Consideration of discount rates (DR-with) resulted the same as: $92,5 \%(\mathrm{v} 1) ; 81,1 \%(\mathrm{v} 2) ; 76,6 \%(\mathrm{v} 3)$. The reached power saving for all control methods of blower regulation are inside range $14,3-34,9 \%$.
\end{abstract}

\section{Introduction}

The blower systems, used for communal water and wastewater utilities, are typically largest consumers of electrical energy at a wastewater treatment plants (WWTPs) after pumping station facility consumers. When management controls energy uses and technical performances inefficiencies can be noticed and corrected with benefit to utilities.

All further references will provide access to pneumatic aeration systems with respect to centrifugal blower applications, that is more typical for large WWTPs construction and design. Russian example shows, that electrical consumption is up to $80 \%$ of the total capacity of the municipal WWTPs with biological process, and the introduction of blower control in practice reduces energy consumption by at least $35 \%[1,2]$.

As for European WWTPs with advanced nutrient removal aeration consumes about $60 \%$ of the total energy use, with refer to full-scale energy savings in the range of $16-20 \%$

\footnotetext{
* Corresponding author: bazhenov@pump.ru
} 
could be achieved [3]. Other European analysis shows a significant energy efficiency potential up to $25 \%$ [4]. An Italian experience [5] include perspective "the most consistent energy savings in water line can be achieved for aeration systems in the biological section" with reefer to energy saving up 20-36\% and payback period of 2,4-5 years.

Energy consumption at a typical municipality in the U.S. "requires for aeration $60 \%$ or more of the overall power consumption at WWTPs" and energy savings in excess of 35\% "can easily be achieved by replacing existing conventional blower technology with directdrive turbo blowers" [6]. Furthermore, even greater energy savings, up to $15-20 \%$, could also be achieved with automatic dissolved oxygen (DO) control. The overall and fundamental conclusion represent the complex opinion "It is estimated that aeration energy consumption can be $50-90 \%$ of the total energy demand of an activated sludge process" [7, page 1484].

The cost management: capital and operating, blower efficiency and turndown capability should be in priority during selection of an appropriate blower type. The main technological trends for control strategies are [1, 2, 6-8]: inlet and discharge throttling by control valve; blower speed control by frequency converter or VFD; single or dual vane control blower throttling by inlet guide vanes (IGV) or discharge guide vanes (DGV), also named as variable diffuser system. Reference [8] supplied by key values of Aeration Efficiency, kg $\mathrm{O}_{2} / \mathrm{kWh}$, for fine-pore/course bubble aeration: standard conditions 5,0-6,5/2,5-3,5; field conditions 2,5-3,5/1,0-2,0. Data includes blower power requirements, that keeps practical usage. In comparison to manual control automatic DO control conserve $20-40 \%$ of aeration energy.

The review [9] describes the air supply system for blower stations with piping and valve (types: butterfly, damper, globe, plug, etc.) control. Valve opening controls by actuator (pneumatic or electric) by means of the control signal. Best way to minimise the pressure loss through the air supply system - the most-open-valve concept (MOV). Design criteria for aeration systems, affecting diffuser transfer efficiency are: layout, density, age, and sludge retention time [10].

Life cycle costs (LCC) should be analysed and conducted for various blower types and system configuration before a final selection is made, during modifying of existing systems or new construction design procedure. Collected from practice inefficient energy and cost data can fund new and higher efficiency solutions through the expanses recovered from the inefficient processes.

Pumping station design on the basis of LCC analysis is a standard tool for pump manufacturer companies and conjugate (pipelines, valves) equipment, as well as designers. That is easy to determine by analysing the publications, for example through magazine "World Pumps". This is quite close direction to follow blower station design.

As for LCC analyses itself, the different models have been reviewed [11] in a detailed way with advantages and disadvantages. These models are rather complex and requires bit knowledge for investigation by ordinary engineer (not economist) its differences. That's why a conceptual discussion of LCC approach [12] followed by conclusion "LCC does not take into account the decision makers, limited ability to make rational decisions under uncertainty". We must pay tribute to the fundamental nature of these studies, the conclusion is not useless, since it is supported by tools - three research solutions are proposed.

The main goal of LCC analyses is to choose the option, which would provide the lowest cost for the estimated period of the economy. The assessment is carried out on the examples of municipal WWTPs $[13,14]$ and directly blower stations. For blower stations are not developed clear guidelines for the identification and definition of life cycle cost indicators, that is the subject of this study. The relevance of these studies should be supplemented by the urgent need for similar methodological development not only for tender procedures, but also for energy service and leasing contracts $[15,16]$. 
The goal of the LCC methodology development in Russia is to optimize the procedures for selecting a technical variant, that will ensure the efficiency of water and wastewater communal utility for the entire calculation period. The objectives of the methodology should satisfy tender estimation of competitive procedures for technical and technological solutions. That would reduce reasonable customer expanses in the conditions under development of fair competition; ensuring that the calculation results are unambiguous and transparent.

\section{Materials and methods}

There are detailed options for life cycle cost estimation techniques, including: Full cost accounting (FCA), Full cost environmental accounting (FCEA), Total cost assessment (TCA), Life cycle accounting (LCA), Life cycle cost assessment (LCCA), Life cycle costing (LCC), Full cost pricing (FCP), Whole life costing (WLC). These documents have been developed for 20-30 years by large teams of specialists, then discussed, their structure improved as a result of discussions.

The methodology for estimating the Whole life costing (WLC) is presented by the international standard ISO 15686-5:2017 [17]. The WLC method integrates extra indicators (external factors; non-construction costs; revenues), which may not be useful for public procurement, excessive data will only complicate the decision-making process, figure 1.

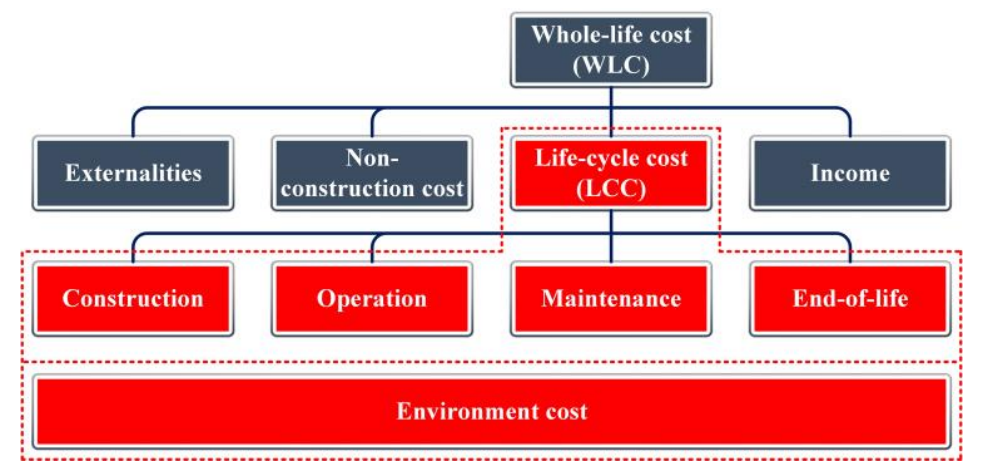

Fig. 1. The structure of the Whole life costing (WLC) with the allocation zone of Life cycle cost (LCC) shows the difference between WLC and LCC.

Some presented methods include costs, which cannot be subject of public procurement:

- FCP methodology is designed not for public corporations, but for commercial businesses. The mechanism of calculation for these companies structures direct costs per unit of production plus the overheads (profit and overheads);

- Methods with the term "Assessment" (TCA, LCCA) address environmental aspects and potential environmental impacts throughout the product life cycle from raw material extraction to product disposal. These standards are not intended for contractual or regulatory purposes;

- Methods FCA, FCEA, TCA, like the previous ones, are related to the "green economy" (they process information on the possible costs of alternatives - ecological, social and economic). Experts consider the terms "True" and "Full" to be problematic, since these definitions are inherently subjective.

The priority direction of methodological development should be a structured application of the costs included in the LCC for procurement procedures of water and wastewater communal utility. Such a mechanism is Life Cycle Costing (LCC), or an economic 
estimation method, that takes into account all relevant costs over a specified accounting period, including adjustments to the time value of money. The most detailed development and the closest analogue for blower stations are taken as a basis - Pump life cycle costs [18].

For this study was adopted one more method of dynamic simulation of WWTP for the design purpose with respect to ASM1 model [19]. Russian practice is described in [20] and its application for blower stations allows to get results with daily and annual control of blowing equipment [21] with advanced tool GPS-X (Hydromantis ESS, Inc.).

\section{Essence of study and Results}

For Russian conditions was carried out the development of "Methodology of life cycle cost estimation for equipment, systems and structures for water and wastewater utilities". The developers are convinced, that the resulting document is simple and understandable for use by water service sector [22]. The document is ready for state standardization procedure.

The goal of the research was to compare the methods of technologically uncontrolled and controlled air supply for aeration systems in the conditions of new construction of the blower station building, with and without discount rates of investment project cash flows.

The tasks of the research were to perform economic analysis in the conditions of fluctuations (daily and annual) of air supply to pneumatic aeration systems, supplied with large centrifugal air blowers (multistage and single-stage with vane control).

During development different trends been studied, like its application to fit blower station design [21, 23], or usage of ASM1 dynamic model simulation as input to LCC analyses. The need for dynamic modeling is obvious - to create imitations of daily and annual fluctuations for DO conditions. That would support air flow requirements for blowing equipment - same fluctuation conditions for different variants:

- variant 1 - without control strategy of blower regulation (for comparison purpose);

- variant 2 - blower speed control by frequency converter;

- variant 3 - blower dual vane control by inlet and discharge guide vanes (IGV+ DGV).

Regulation of air flow is expected to generate significant energy savings.

\subsection{Provision of input data for LCC analyses}

The capital part of expenses is formed according to the standard Russian design 902-1135.88 "Pump-and-blower station with 8 turbochargers TV-300-1,6". All variants include reserve equipment, that is building regulations and local standard.

For economic analysis was chosen the project with relative capacity 300 thousand $\mathrm{m}^{3} /$ day with an average air supply uniformity to the aeration tanks of $7 \mathrm{~m}^{3} / \mathrm{m}^{3}$ (figure 2 ), which corresponds to calculated values of air flow, $\mathrm{m}^{3} / \mathrm{h}$ : maximum $-107114,76$; average - 87 500; minimum - 58 107,23. Duty overpressure is 0,6 bars, including losses at air distribution system. Performance curves been requested from producers. Commercial details, even producer company names, are missed, with respect to: scientific publication, priority to control methods of regulation. For estimation of required blower's capacity, the variations of air flow were calculated under conditions of highest temperatures. Figure 3 shows the operation of the units under the conditions of the accepted daily fluctuations of the air supply. 


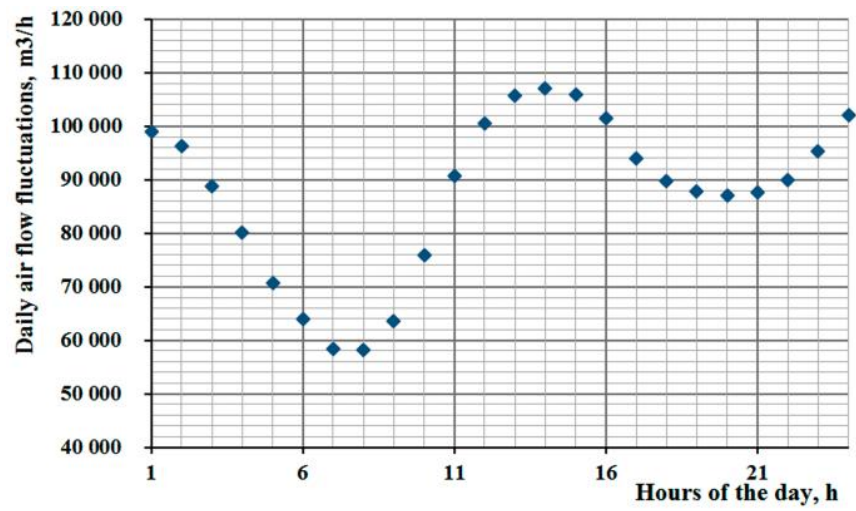

Fig. 2. Calculated daily fluctuations of air supply to air aeration systems for standard conditions.

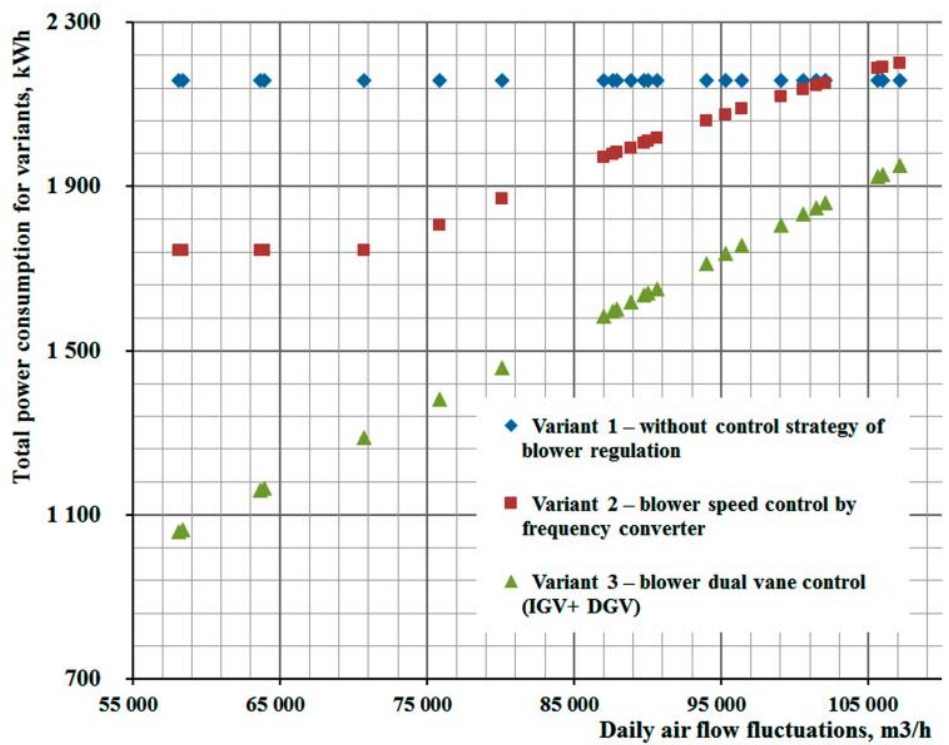

Fig. 3. Power performances of blower units according to the given daily fluctuations of air supply (for standard conditions).

It is visible, that variant 3 keeps smaller power consumption up to single-stage nature of blowers and large range of flow regulation. For variant 2, when the air flow is less than 71 thousand $\mathrm{m}^{3} / \mathrm{h}$, there is an overdraft on both flow and power consumption (range limit of flow regulation due to surge risk). Furthermore, on the top flow variant 2 needs extra power to compensate frequency converter losses (total power consumption means network power). Also, important to comment, that applied multistage blowers have 4 stages. Power consumption within the control range (variants: $1 ; 2 ; 3$ ), kWh: 2158,16; 1743,16-2201,58; 1058,65-1951,51. Input data with annual fluctuations of air temperatures were estimated from standard conditions to Moscow region conditions.

\subsection{LCC analyses of blower station major costs}

Mentioned methodology [22] presented by us with consideration of main indicator costs due to present research study, table 1 . For example, the costs $\mathrm{Cs}$, Cenv, Cd were excluded because of their identity due comparison variants. 
Table 1. Complete list of life cycle indicators with consideration of main indicator costs.

\begin{tabular}{|c|c|c|}
\hline Identifier & Essence & $\begin{array}{c}\text { Consideration } \\
\text { in study }\end{array}$ \\
\hline \multicolumn{3}{|c|}{ Components of capital costs (CAPIT) } \\
\hline Cic & $\begin{array}{c}\text { Initial costs, purchase price (blower, system, pipe, auxiliary } \\
\text { services) }\end{array}$ & + \\
\hline$C i n$ & Installation and commissioning costs & + \\
\hline \multicolumn{3}{|c|}{ Components of operation and maintenance costs $(O \& M)$} \\
\hline$C e$ & $\begin{array}{c}\text { Energy costs (conditions: tariff for electricity - 3 rub/kWh, annual } \\
\text { tariff increase - 1,5\%, input power - Pin) }\end{array}$ & + \\
\hline$C o$ & Operation costs (labor and supervision costs) & + \\
\hline$C m$ & Maintenance and repair costs & - \\
\hline$C s$ & Down time costs (loss of profit due to productivity loss) \\
\hline$C e n v$ & Environmental costs (expanses preventing damage) & - \\
\hline \multicolumn{2}{|c|}{ End-of-life costs } \\
\hline$C d$ & $\begin{array}{c}\text { Decommissioning/disposal costs (utilization and recycling costs, } \\
\text { residual value of equipment for its future use) }\end{array}$ & - \\
\hline
\end{tabular}

The presented equations determine the estimation of the main indicators as constituting elements of LCC, with (formula 1) and without (formula 2) discount rates (DR) of investment project cash flows:

$$
\begin{gathered}
L C C=(\mathrm{Cic}+\mathrm{Cin})+(\mathrm{Ce}+\mathrm{Co}+\mathrm{Cm}) \text { or } L C C=\sum C A P I T+\sum O \& M \\
L C C=\sum C A P I T(\mathrm{Cic}+\mathrm{Cin}) /(1+r)^{n}+\sum O \& M(C e+C o+C m) /(1+r)^{n}
\end{gathered}
$$

where:

$n$ - calculation period (accepted as expected life-time -25 years) or rate period for discount operations;

$r=(i-p)-$ discount rate (accepted 5\%), part of unit;

$p$-inflation rate (accepted $15 \%$ ), part of unit;

$i$ - bank deposit interest rate (accepted $20 \%$ ), part of unit.

Table 2 and figure 4 represent the results of comparative analysis for variants with and without discount rates. Project details: the price of APCS and instrumentation for aeration tanks (variants 2, 3) - 71,79 $\mathrm{mln}$. rub; price of cooling system of frequency converter (variant 2) - 1,5 mln. rub; one replacement of frequency converter, capacitors, fans (variant 2) was taken into account for period 25 years.

Table 2. Comparative economic analysis of technical variants ( $n=25$ years), mln. rubles.

\begin{tabular}{|c|c|c|c|}
\hline Identifier & Variant 1 & Variant 2 & Variant 3 \\
\hline \multicolumn{4}{|c|}{ Without consideration of discount rates } \\
\hline Cic + Cin & 62,56 & 162,49 & 173,58 \\
\hline$C e$ & 1705,06 & 1461,22 & 1109,47 \\
\hline$C o$ & 18,00 & 18,00 & 18,00 \\
\hline$C m$ & 10,04 & 34,99 & 11,90 \\
\hline$L C C$ & 1795,66 & 1676,70 & 1312,95 \\
\hline \multicolumn{4}{|c|}{ With consideration of discount rates (DR), r= (i-p) $=5 \%$} \\
\hline$C i c+C$ in & 62,56 & 162,49 & 173,58 \\
\hline$C e$ & 960,97 & 823,54 & 625,30 \\
\hline$C o$ & 10,14 & 10,14 & 10,14 \\
\hline$C m$ & 5,66 & 19,72 & 6,71 \\
\hline$L C C$ & 1039,34 & 1015,90 & 815,73 \\
\hline
\end{tabular}




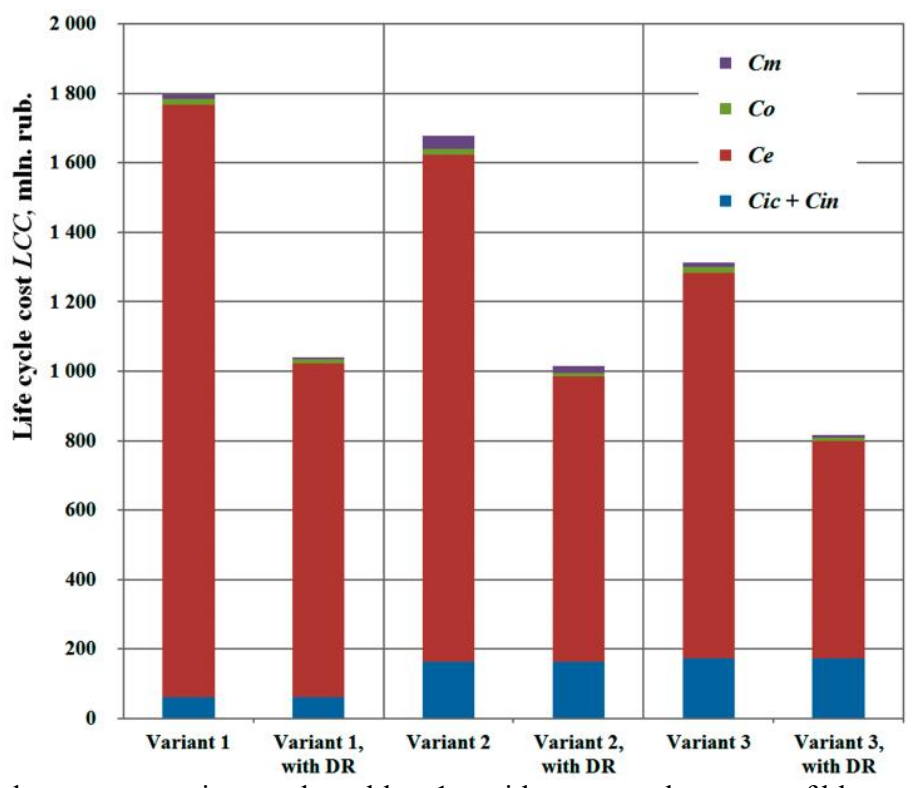

Fig. 4. Life cycle costs per variants, mln. rubles: 1 - without control strategy of blower regulation (for comparison purpose); 2 - blower speed control by frequency converter; 3 - blower dual vane control by inlet and discharge guide vanes (IGV+ DGV). DR - discount rate.

The most attractive investment project is variant 3 with control based on the dual vane control (IGV+ DGV), that shows the energy economy 34,9\% in comparison with control variant 1. According to LCC estimations the economy reached without/with DR, \%: $26,9 / 21,5$. This case should be noted also as single-stage nature of blowers and large range of flow regulation.

For variant 2 the energy economy constitutes $14,3 \%$ in comparison with variant 1 without regulation. That case is a comparison of multistage blowers with 4 stages. There is an overdraft on both flow and power consumption, caused by range limit of flow regulation due to surge risk. Daily density of duty points is concentrated at the flows close to maximal (figure 3). At the same zone variant 2 needs extra power to compensate frequency converter losses (accepted as 2\%). At night time (corresponding flows $55000-87000 \mathrm{~m}^{3} / \mathrm{h}$ ) daily density of duty points is less, so its less influence to the total power saving. Basically, it relates to daily fluctuations of air supply (figure 2). In order to increase duty control range of multistage blowers, equipped with VFD, the selection of motor should be with extra power. According to LCC analyses the economy reached without/with DR, \%: 6,63/2,26. So, energy savings are bit compensated by capital and O\&M expanses (last one requires one-time replacement of frequency converter, capacitors, fans due to period 25 years). O\&M schedule includes also care of interstage seals, in order to compensate the drop of efficiency.

Generally, reached power saving for control methods are inside range 14,3-34,9\%. Reached LCC economy without/with DR, \%: 6,63-26,9/2,26-21,5\%. Note: control methods refer not only to blower costs and expenses, as well to APCS and instrumentation for aeration tanks.

\section{Conclusion}

Blower stations for wastewater utilities should be designed under forecast of economic asset management through construction of Life Cycle Cost analysis. The reason is, that 
management of construction design serves for energy-saving control strategies. The construction budget, based on one-time costs and prices, pays less attention to water and wastewater utilities. Furthermore, the cheapest equipment cost would provide the negative impact, contained inefficient energy expanses.

The powerful units, like blower stations, less investigated by means of economical sustainability instruments of utilities. Control strategy for blower stations of wastewater treatment plants is a powerful way to maximize the benefit of management financial resources: available capital and always limited maintenance and operation costs.

LCC analyses refer to its application with and without consideration of discount rates (DR, DR-out, DR-with). Also investigated variants of blower types: multistage without control (v1), multistage with VFD control (v2), single stage dual vane control (v3). The result of LCC analysis (DR-out) shows, that last variant 3 is most cost-effective for investments with economy of: $26,9 \%$ to (v1) and $21,7 \%$ to (v2) under the identical duty conditions. Consideration of discount rates (DR-with) resulted the same as: $21,5 \%$ to (v1) and $19,7 \%$ to $(\mathrm{v} 2)$.

The power consumption plays a significant role in LCC estimation. The result of LCC analysis (DR-out) shows the proportion "energy/LCC": 94,9\% (v1); 87,1\% (v2); 84,5\% (v3). Consideration of discount rates (DR-with) resulted the same as: $92,5 \%(\mathrm{v} 1) ; 81,1 \%$ (v2); 76,6\% (v3). The reached power saving for all control methods of blower regulation are inside range $14,3-34,9 \%$.

\section{References}

1. S. E. Berezin, Water Supply and Sanitary Technique, 3, 55 (2012)

2. S. E. Berezin, Water Supply and Sanitary Technique, 11, 59 (2012)

3. L. Rieger, I. Takacs, H. Siegrist, Water Environ. Res., 84 (2), 170 (2012)

4. D. Torregrossa, F. Hernández-Sancho, J. Hansen, A. Cornelissen, T. Popov, G. Schutz, Journal of Cleaner Production, 167, 601 (2017)

5. D. Panepinto, S. Fiore, M. Zappone, G. Genon, L. Meucci, Applied Energy, 161, 404 (2016)

6. K. Y. Bell, S. Abel, Water Practice \& Technology, 6 (2), (2011)

7. B. G. Liptak, Instrument Engineers' Handbook, Fourth Edition, Volume Two: Process Control and Optimization (CRC Press, 2006)

8. G. Crawford, J. Sandino, Energy efficiency in wastewater treatment in North America: a compendium of best practices and case studies of novel approaches (WERF, 2010)

9. L. Åmand, G. Olsson, B. Carlsson, Water Science \& Technology, 67 (11), 2374 (2013)

10. D. Rosso, M. K. Stenstrom, L. E. Larson, Water Science and Technology 57 (7), 973 (2008)

11. S. K. Durairaj, S.K. Ong, A.Y.C. Nee, R.B.H. Tan, Corporate Environmental Strategy, 9 (1), 30 (2002)

12. P. Gluch, H. Baumann, Building and Environment 39, 571 (2004)

13. E. S. Gogina, F. D. Gurinovich, Water Supply and Sanitary Technique, 9, 36 (2016)

14. V. I. Bazhenov, N. A. Krivoshekova, Water Supply and Sanitary Technique, 2, 69 (2009)

15. S. E. Berezin, V. I. Bazhenov, A. V. Ustuzhanin, M. A. Kuksa, V. I. Petrov, Yu. V. Petrov, B. V. Ovseitchuk, I. A. Noskova, Best Available Technologies of Water and Wastewater, 1, 32 (2016). 
16. S. E. Berezin, V. I. Bazhenov, A. V. Ustuzhanin, M. A. Kuksa, V. I. Petrov, Yu. V. Petrov, B. V. Ovseitchuk, I. A. Noskova, Best Available Technologies of Water and Wastewater, 2, 40 (2016).

17. ISO 15686-5:2017, Buildings and constructed assets - Service life planning - Part 5: Life-cycle costing (2017)

18. Pump Life Cycle Costs: A Guide to LCC Analysis for Pumping Systems (Hydraulic Inst, 2001)

19. M. Henze, W. Gujer, T. Mino, M. van Loosdrecht, IWA Scientific and Technical Report, 9, (IWA Publishing, 2000)

20. V. I. Bazhenov, A. N. Epov, I. A. Noskova, Water Supply and Sanitary Technique, 2, 62 (2014)

21. V. I. Bazhenov, S. E. Berezin, A. V. Ustuzhanin, Water Supply and Sanitary Technique, 2, 46 (2015)

22. V. I. Bazhenov, E. I. Pupurev, G. A. Samburskiy, S. E. Berezin, Water Supply and Sanitary Technique, 2, 10 (2018)

23. V. I. Bazhenov, A. V. Ustuzhanin, Vestnik MGSU, 9, 146 (2015) 